\title{
CORRECTION
}

\section{Correction to: Metastasectomy for visceral and skeletal oligorecurrent prostate cancer}

\author{
Antonino Battaglia ${ }^{1} \cdot$ Gaëtan Devos ${ }^{1} \cdot$ Karel Decaestecker $^{2} \cdot$ Manuel Witters $^{1} \cdot$ Lisa Moris $^{1} \cdot$ Thomas Van den Broeck $^{1}$. \\ Charlien Berghen $^{3}$. Wouter Everaerts ${ }^{1}$. Maarten Albersen ${ }^{1} \cdot$ Arman Tsaturyan $^{4}$. Gert De Meerleer ${ }^{3}$. \\ Hein Van Poppel ${ }^{1} \cdot$ Karolien Goffin $^{5} \cdot$ Piet Ost $^{6} \cdot$ Lorenzo Tosco $^{1,5,7} \cdot$ Steven Joniau ${ }^{1}$
}

Published online: 27 March 2020

(c) Springer-Verlag GmbH Germany, part of Springer Nature 2020

\section{Correction to: \\ World Journal of Urology (2019) 37:1543-1549 \\ https://doi.org/10.1007/s00345-019-02716-8}

The authors have requested the removal of the Excel file in Electronic Supplementary Material of the original article to protect patient's privacy. Hence, the contents in the Excel file were removed and replaced with the following text:

Unfortunately, we had to remove the original Excel file in Electronic Supplementary Material, because of changed privacy legislation.
Publisher's Note Springer Nature remains neutral with regard to jurisdictional claims in published maps and institutional affiliations.

The original article can be found online at https://doi.org/10.1007/ s00345-019-02716-8.

Steven Joniau

steven.joniau@uzleuven.be

1 Department of Urology, University Hospitals Leuven, Herestraat 49, 3000 Louvain, Belgium

2 Department of Urology, University Hospital Ghent, Ghent, Belgium

3 Department of Radiation Oncology, University Hospitals Leuven, Louvain, Belgium

4 Department of Urology, Astghik Medical Center, Yerevan, Armenia

5 Nuclear Medicine and Molecular Imaging, KU Leuven, Louvain, Belgium

6 Department of Radiation Oncology and Experimental Cancer Research, Ghent University, Ghent, Belgium

7 Department of Urology, Humanitas Gradenigo Hospital, Turin, Italy 